\title{
Paleohispánico: una aproximación al primer periodo castellano en México
}

\section{Paleohispanic: An Approach to the First Castillan Period in Mexico}

Rodrigo Octavio Tirado de Salazar ${ }^{1}$

Recibido: 15-11-2018

Aceptado: 21-09-2019

\begin{abstract}
Resumen
El periodo del primer contacto cultural entre castellanos y mexicas no está delimitado y en realidad el término "Periodo Colonial" es demasiado vago, ya que engloba y homogeniza 300 años. Por otro lado, el término "Novohispano" al igual que el término "Virreinal" son términos que dan nombre al periodo que inicia con la llegada del primer virrey don Antonio de Mendoza. Es por esto que es necesaria una buena delimitación del término que denomina el lapso que comienza en el momento justo en que termina la guerra de conquista (1521) y que concluye con la llegada del primer virrey (1535), período en que entraron en contacto los conquistadores españoles con la cultura mexica es decir, la cultura castellana con la cultura mexica.
\end{abstract}

\section{Palabras clave:}

Ciudad de México, urbanismo americano, virreinal, CDMX, México Colonial, México.

\begin{abstract}
The period of cultural contact between Spaniards and Aztecs is not delimited and in fact the term "Colonial Period" is too vague because it includes 300 years of history and archaeology. On the other hand, the terms "Novohispano" as well as the term "Viceroyalty" are words that give name to the period that begins with the arrival of the first viceroy Don Antonio de Mendoza. This is why a good delimitation and naming of the stage which begins at the exact moment in which the Conquest War of Mexico ends (1521) and concludes with the arrival of the first viceroy (1535) is needed. This period would frame the moment in which Spanish conquistadors and their Castilian culture came into contact with the Aztec culture.
\end{abstract}

Key words:

Mexico City, American Urban Planning, Colonial Mexico, CDMX, Viceroyalty, Mexico.

1 Escuela Nacional de Antropología e Historia, México D.F.; email:rodrigotisa@gmail.com; orcid.org/0000-0002-3174-7612. 


\section{INTRODUCCIÓN}

El periodo de tiempo que comprende la primera ciudad de México resulta especialmente complicado, ya que se encuadra en el límite entre dos etapas temporales de la realidad europea. Es decir, la primera ciudad de México surge dentro del marco del principio de la Edad Moderna y el final de lo que se conoce como Edad Media. Por lo tanto, resulta muy complicado encuadrarla dentro de alguno de estos periodos aunque, recurrentemente, los estudios de este lapso temporal son trabajados desde la óptica moderna, mientras que los estudios medievales han sido muy escasos.

Desde el punto de vista americano -mexicano y estadounidense, especialmente- el periodo que nos interesa parece estar enclavado dentro de una amalgama llamada "Periodo Colonial" (Gosden, 2004: 14). Esta denominación temporal resulta muy vaga, ya que abarca desde el primer momento en que entraron en contacto la población castellana con la indígena hasta la independencia de México a principios del siglo XIX. En otras palabras, el llamado "Periodo Colonial" resulta insuficiente para explicar el momento histórico en el que se planeó y construyó la ciudad de México.

Otro aspecto que debo mencionar es que dentro del "Periodo Colonial" se enmarcan distintas etapas, como son el periodo "Novohispano" y el "Virreinal", que designan momentos muy específicos dentro de la historia de México.

No obstante, el periodo novohispano, no incluye el tiempo en que se planeó y construyó la ciudad de México y, del mismo modo, el término "Virreinal" es desatinado porque, en este caso, comenzará con la llegada del primer virrey en el año de 1535 , mismo año que nos servirá de límite máximo para designar al periodo a tratar.

En concreto resulta evidente que existe una falta de matización terminológica que, como consecuencia, conduce a un problema temporal que entorpece las investigaciones que se realizan sobre los primeros momentos que sucedieron al contacto entre la cultura castellana y la mexica.

Una de las mejores aproximaciones con las que contamos hasta ahora fue el intento de Lucía Mier y Terán en su libro titulado La primera traza de la ciudad de México 1524-1535. En el trabajo citado, ella trató de nombrar este periodo como "Periodo formativo de la organización espacial de la ciudad de México" (2005: 29). No obstante, resulta que este término, aunque es indicado para el primer urbanismo de la ciudad y sirve perfectamente para ello, es limitado, ya que no puede extrapolarse a otros territorios, y no nos sirve a la hora de distinguir los procesos culturales que se dieron a principios del siglo XVI, cuando entraron en contacto dos culturas que jamás habían tenido noticia la una de la otra. Es decir, que el término "Periodo formativo del espacio urbano de la ciudad de México" limita el estudio a dicha población y a la disciplina del urbanismo, dejando, así, fuera y sin terminología propia al periodo americano que se encuadra entre el fin de los gobiernos indígenas y la llegada del modelo virreinal.

Por este motivo, propongo la utilización del término "Paleohispánico" para designar el periodo que nos ocupa, que, en el caso de la ciudad de México, coincide con el "Periodo de formación del espacio urbano de la ciudad de México" de Mier y Terán y que se caracteriza por la ausencia de autoridades que representen a la metrópoli porque la autoridad está representada por los mismos conquistadores, mientras que las funciones religiosas e ideológicas son llevadas a cabo por las órdenes mendicantes y no por la institución eclesiástica europea.

El término Paleohispánico significa, literalmente, antiguo español o viejo español, ya que cuenta con el prefijo "paleo" que viene del griego y significa viejo o antiguo. Es así como el Paleohispánico abarcará desde el establecimiento de los conquistadores castellanos en los territorios mexicas. Es decir, una vez terminada la guerra de conquista en el año de 1521, hasta la llegada de Antonio de Mendoza, primer virrey de la Nueva España, el año de 1535. Por lo que la primera ciudad de México, que va de 1524 a 1535, quedará dentro de este periodo, el cual coincide con el previo a la cristalización cultural después de la cual, según Mier y Terán, quedó definida la cultura Novohispana.

Una de las formas cómo podemos aproximarnos y comenzar a comprender los procesos culturales que afectaron al territorio mexica a principios del siglo XVI es por medio de la llamada "Teoría de la aculturación".

\section{Teoría de aCulturación}

La "Teoría de la aculturación", que ha dominado los estudios antropológicos desde las primeras décadas del siglo XX, fue elaborada a partir de los planteamientos de historiadores y antropólogos como Franz Boas, Melville J. Herskovits, Robert Redfield, Ralph Linton y George M. Foster, entre otros.

A grandes rasgos, esta teoría plantea que en la interrelación entre culturas distintas se produce un proceso de asimilación bipartita, que va configurando una cultura nueva, resultado de esa síntesis. 
De hecho, ése es el punto de partida del propio proceso de aculturación-asimilación. Pero en una situación de colonialismo, la cultura dominante tiende a imponer sus rasgos que, a la larga, hegemonizarán el proceso.

Esta teoría parecía estar superada hoy en día, ya que supone que la aculturación es inevitable y que, tarde o temprano, terminará imponiéndose la cultura colonizadora, extinguiendo así los rasgos culturales diversos (Fábregas, 2012: 1), hasta lograr una homogeneización absoluta de la cultura, produciendo una copia total de la primera.

Para sorpresa de muchos, la llamada "Teoría de la aculturación" no está superada, sino que fue matizada. La causa de su supuesta superación fue el surgimiento de diversas teorías contemporáneas, como son la "Teoría de la multiculturalidad", la "Teoría de la Interculturalidad" y la "Teoría de la transculturalidad" que, hoy en día, se utilizan para describir y analizar a las sociedades contemporáneas, dentro del fenómeno de la globalización. Sin embargo, para estudiar el contacto entre culturas antiguas y los cambios culturales que éste produjo, la teoría de la aculturación sigue siendo una teoría vigente, aunque siempre con sus debidos matices y actualizaciones.

Por ese lado, la tendencia antropológica desde la mitad del siglo XX ha sido excluir a la cultura occidental del estudio del proceso de aculturación (Steward, 1945: 199), por lo que el punto de vista del análisis siempre será el del "conquistado", sin tomar en cuenta los rasgos culturales que portaba "el conquistador".

Para George Foster, la aculturación estaría constituida por un grupo de mecanismos socioculturales y psicológicos, conforme a los cuales operan los cambios que se implican cuando se ponen en contacto dos o más culturas (Foster, 1962: 27). La gran contribución de este pensador al estudio de la aculturación puede resumirse en el término cultura de conquista, el cual nos ayuda a comprender la naturaleza de la cultura dominadora y la forma en que esta se presenta frente a la cultura dominada.

Es así como la aculturación tiene que ser comprendida, como un proceso bipartito, en el que la cultura dominada contribuye a la aculturación con la misma intensidad con la que contribuye la cultura dominadora (Foster, 1962: 30). Esto significa que:

No es solo que los colonizadores cambien a los colonizados, pues ambas categorías no existen en su forma elemental, sino más bien que todos los implicados son cambiados por el proceso de circulación, tanto si viven dentro como fuera de los centros simbólicos. (Gosden, 2004: 16)
Para hacer una nueva propuesta que complemente la "Teoría de aculturación", Foster nos plantea ciertas preguntas con el objetivo de acercarnos al estudio de la cultura de conquista. Algunos ejemplos de preguntas son: ¿de qué se habla en realidad cuando se alude a la cultura española en América Latina?, ¿de personas como los conquistadores, los colonizadores, los misioneros o los administradores gubernamentales?, ¿de las ideas?, ¿de la cultura material?, ¿de la totalidad de modelos culturales españoles desde el siglo XI al XVIII? En suma: ¿cuál fue la "norma española de vida" que, llegando a América como una fuerza de aculturación, produjo la civilización hispanoamericana, y cómo estaba formada? (Mier y Terán, 2005: 52).

Estas preguntas han sido retomadas en los últimos años por la óptica posestructuralista y hemos comenzado a cuestionarnos el origen cultural de los modelos establecidos. Es decir, la cultura de conquista se forma partir de un doble proceso de selección. El primero de ellos tiene que ver con el grupo dominador, el cual seleccionará las partes que le parezcan más importantes de su cultura para que sean transmitidas a la cultura dominada. El segundo involucra directamente a la cultura dominada, la cual seleccionará cuáles serán los rasgos culturales que retendrá de la cultura dominadora.

Esta doble selección implica gran cantidad de rasgos culturales, dentro de los cuales, según Foster, deberían incluirse los que encontramos en la España pluricultural de hoy en día. De esta manera, solamente algunos de los rasgos regionales habrían pasado al nuevo mundo y, después de esa selección, una pequeña porción de ellos se habría mantenido después del proceso de aculturación.

Es así como Foster llama Cultura de Conquista al conjunto de influencias donadoras, provengan de donde provengan, que estarán en contacto con la cultura receptora. Por medio de ésta llegarán al grupo receptor los valores y normas del grupo donador. De esta forma, la cultura de conquista se presenta como el resultado de un proceso en que una nueva versión de la cultura donadora comienza a partir de la infinita variedad de formas, que son originales, y se enriquece con los elementos que la propia situación de contacto produce.

Resulta fundamental mencionar que la cultura de conquista nacerá a partir de los procesos de selección formal e informal ya que dichas selecciones tendrán consecuencias muy diferentes.

Los procesos formales tendrán que ver directamente con las instituciones y los individuos que, de manera activa, hacen una selección cultural por medio de ciertos planeamientos. Los mejores ejem- 
plos de este tipo de instituciones son la Iglesia, el Gobierno y los oidores. Lo formal, en este caso, será lo planeado o dirigido con metas específicas.

Por otro lado, los procesos informales tendrán la característica de la falta de ordenamiento, serán espontáneos y, por lo tanto, orgánicos, ya que no tendrán un tipo premeditado. Algunos de los mejores ejemplos de procesos informales serán la superstición, las creencias y prácticas religiosas, así como la medicina popular y la historia oral.

Para el caso concreto de la ciudad de México, Foster propone que, dentro del proceso de aculturación, la población indígena aceptó la nueva cultura material, al igual que las técnicas aportadas por la población peninsular en función de su utilidad, ya que éstas son rechazadas cuando la población preexistente cuenta con sistemas o herramientas más eficientes (1962: 389-402). Los ejemplos que ese autor utiliza están relacionados, directamente, con la explotación de la tierra y el ámbito ganadero, cuando la técnica del arado, las herramientas y la explotación del trabajo por medio de los animales sustituyeron rápidamente a la coa.

Por otro lado, dentro del proceso de aculturación, existe un límite temporal, en el cual puede notarse cierto derretimiento de las estructuras culturales previas; por lo tanto, en dicho espacio de tiempo, se favorece la mezcla entre la cultura dominadora y la cultura dominada.

Sobre este espacio temporal, Lucía Mier y Terán hace mención de un proceso que ella llama cristalización cultural, donde el derretimiento de las estructuras culturales previas al contacto y, como consecuencia, la mezcla entre cultura donadora y receptora, se detiene, por lo que el proceso de aculturación completo disminuye su velocidad y la profundidad con que penetran sus acciones es cada vez mucho menor (2005: 57). Es decir, que de cierta manera hay una petrificación en el proceso de contacto cultural.

En otras palabras, hay cierta dimensión temporal para la presentación de la cultura de conquista, ya que, tras un período de primer contacto, el proceso de cristalización cultural hace que la cultura que fue generada a partir de la mezcla entre dicha cultura de conquista y la cultura preexistente comiencen a extenderse, presentando cierta impermeabilidad con respecto a las dos culturas que la generaron.

De esta forma, resulta que no es el mismo modelo aculturador el de los conquistadores y los frailes de las primeras décadas del siglo XVI, donde ambos tenían el poder absoluto de filtrar y escoger los rasgos culturales que conformarían la parte que Foster llama "proceso formal" de la cultura de conquista, que el modelo virreinal comenzado con la llegada de Antonio de Mendoza en 1535, donde sí podemos hablar de la interacción de la Iglesia y el Estado peninsulares en la conformación del proceso formal de la cultura de conquista (Duverger, 2005: 331).

El espacio temporal al que nos ceñimos en esta investigación para lograr determinar el periodo Paleohispánico está determinado por unos procesos formales de conformación de la cultura de conquista que recaen directamente sobre los mismos conquistadores y funcionarios que se encontraban bajo el poder, muy amplio, de Hernán Cortés (Gibson, 1967: 64) y los frailes que pertenecían a las órdenes mendicantes (Matos, 1975: 117), quienes llevaban una serie de ideas humanistas y universales que, por ejemplo, volvían al catolicismo una religión que podía enseñarse en lengua vernácula (Duverger, 2005: 247).

El caso concreto de la ciudad de México, en tiempos cortesanos, parece caracterizarse por una cultura de conquista menos influida por los procesos formales, que determinarán lo que debía transmitirse o no a la cultura dominada de forma planeada y racional, que por procesos informales dentro de los que se encuentran la espontaneidad y el pragmatismo. Esto lo podemos ver reflejado en la forma de las cerámicas: las llamadas "Azteca IV y V", las cuales conviven con la llamada de forma general, "Cerámica Colonial". El tema de la arqueología y, en concreto, la cerámica como vehículos de estudio del periodo Paleohispánico será retomado más adelante.

Otro de los ejemplos que tenemos para hablar de la diferencia que existió entre la cultura de conquista del periodo paleohispánico y la de tiempos virreinales es que el modelo cortesano consideraba que el náhuatl debería ser la lengua principal y oficial de la Nueva España (Duverger, 2005: 234), lo que va de la mano de la enseñanza del catolicismo en lengua vernácula, que fue una práctica ejercida por los frailes a principios del siglo XVI.

En general, la primera ciudad de México se ve marcada por el pragmatismo y la mayor eficiencia frente a la ciudad de México virreinal, que estará en contacto con las ideas renacentistas y, por ende, tenderá más a la racionalidad y al planeamiento previo (Reyes, 2008: 40) dejando la experiencia de lado.

La cultura de conquista con la que continuó el proceso de aculturación en la ciudad de México, una vez que comenzó el periodo virreinal, estará marcada por la intención uniformadora, desde el punto de vista del proceso formal con que se cons- 


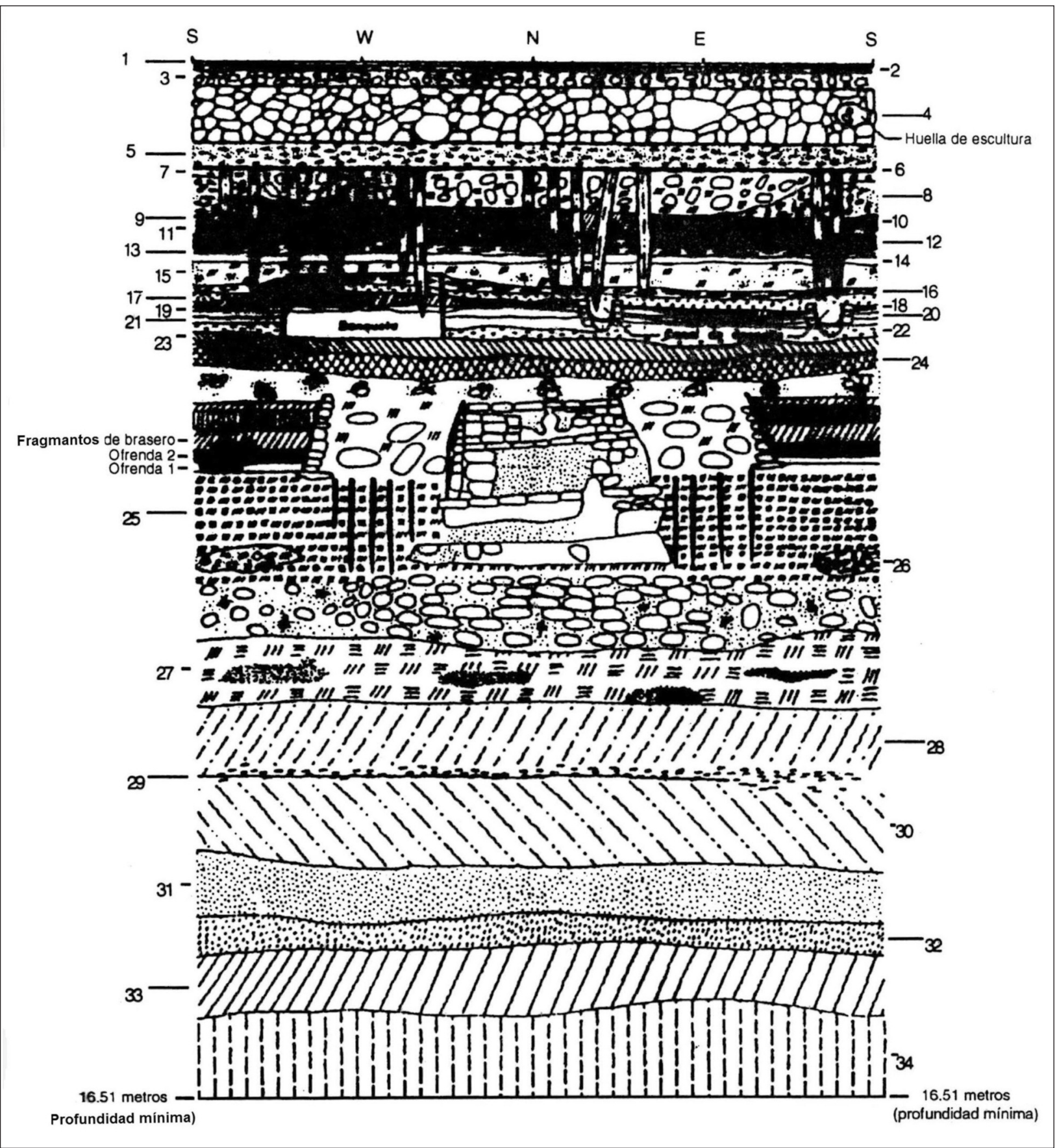

Figura 1. Estratigrafía del sagrario de la catedral metropolitana.

truyó. Es decir, las instituciones como el Estado, que estaba representado por el virrey, y la Iglesia dedicarán gran parte de sus esfuerzos a la uniformidad cultural dentro de la Nueva España. Esto no es en ningún sentido extraño, ya que debemos considerar que la figura del virrey era un intento del emperador para poder controlar los territorios más alejados de forma directa y, así, romper con las estructuras de poder medievales.

Resulta evidente que, para los estudios que realizaba Foster en la década de los 50 y 60, sentía la necesidad de hacer uso de las poblaciones actuales de la Península Ibérica para sustentar los rasgos culturales a los que hace referencia cuando nos habla de cultura de conquista. Sin embargo, sucede que por más que las poblaciones actuales castellanas presenten ciertos rasgos culturales, que resultan ser tradicionales, y que parecen tener correspondencia con su contraparte cultural americana, desde una óptica posestructuralista, que tiende a abrir el panorama de la influencia cultural al máximo de sus posibilidades, resulta muy complicado considerar que 
las fuentes etnológicas actuales, con la división regional contemporánea y la tendencia a la diferenciación dentro de dicha división cultural, nos arrojen un modelo que funcione para lograr comprender, de forma adecuada, a la sociedad castellana del siglo XVI, especialmente considerando los cambios políticos y sociales que ha sufrido España desde la década de 1970.

El presente trabajo se encuadra dentro de la corriente de estudio posestructuralista, donde la aceptación de una multiplicidad de factores, y la consideración del tiempo, y las circunstancias en las que se desenvuelven los eventos históricos, resultan fundamentales para poder comprender procesos tan complejos como son el contacto e incluso el cambio cultural que se llevó a cabo en la ciudad de México a principios del siglo XVI.

Lejos de tratar de resolver en este artículo los temas de la aculturación americana en el siglo XVI y del tipo de influencia que recibieron las culturas indígenas de parte de la población europea, así como en de la manera e intensidad con que dicho aporte fue bilateral, quiero contribuir a la investigación del tema por medio de la apertura del término Paleohispánico para orientar y enfocar toda una nueva serie de investigaciones que están realizándose a principios del siglo XXI.

\section{LA ARQUEOLOGÍA Y EL URBANISMO COMO MEDIDA PARA LOS PROCESOS DE CONTACTO CULTURAL}

Uno de los pilares fundamentales del estudio de procesos culturales lo conforman los datos arqueológicos ya que "la arqueología es la única disciplina que puede cubrir el arco temporal íntegro de las formas coloniales a través de milenios" (Gosden, 2004: 18).

El estudio de la cerámica es fundamental para realizar estudios como éste, porque nos proporciona información sobre el proceso de aculturación. El problema es que los estudios sobre cerámica colonial son muy generales como dice López de Cervantes "La arqueología del periodo colonial de México, en comparación con la realizada para la época prehispánica, es inexistente; además, su múltiple arquitectura no ha sido excavada, sino estudiada por otras disciplinas y, por ende, con otros enfoques". (1979: 44).

En adición, resulta muy complejo el estudio cerámico, comenzando por los problemas terminológicos y temporales como "Los términos "Talavera de Puebla” o "Mayólica hispánica”, e incluso los empleados por Goggin para denominar la loza novohispana, a nuestro parecer deben desecharse, puesto que, por un lado, la propia Talavera de la Reina, en España, reflejó en sus productos la influencia renacentista y oriental, o bien, copió diseños de otros talleres de la mencionada Península" (López Cervantes, 1979:44).

Ciertamente, los estudios realizados hasta ahora no nos resultan suficientes para establecer un estado de la cuestión de la cerámica colonial mexicana de principios del siglo XVI. A pesar de los esfuerzos de Patricia Fournier quién desde la década de los años ochenta ha impulsado notablemente la investigación de la cerámica colonial.

Una de las directrices que podemos seguir es que "A partir de la conquista española, las técnicas de vitrificación, así como el empleo del torno fueron transmitidos a los indígenas a través de la labor educativa de los religiosos o de los artesanos peninsulares como parte del proceso de aculturación" (1979: 53).

Por este motivo, la vitrificación se convierte en un excelente indicador sobre dicha aculturación, que va intensificándose desde el momento de la conquista de México. Es cierto que algunas técnicas indígenas subsistieron, en especial las técnicas del denominado Grupo Pulido, especialmente para la cerámica que era utilizada diariamente.

Por esta razón, López Cervantes piensa que la manufactura de los útiles de cocina para uso común podría haber quedado en manos indígenas mientras los "loceros de lo blanco" siempre fueron peninsulares, o bien, mestizos (1979: 54).

La vitrificación que fue un gran avance para la producción de cerámica desarrollada por la cultura islámica en Cercano Oriente y transmitida a la Península Ibérica de manera natural. Esta técnica permitía la impermeabilización tanto del utillaje de cocina como de las, fachadas que se cubrían de mosaico. En la Nueva España la técnica fue muy utilizada en la región de Puebla y Tlaxcala, donde estuvo muy en auge durante el apogeo del estilo Barroco, hasta la llegada del estilo Neoclásico.

Podríamos pensar que, el fenómeno de la cerámica vitrificada en los estratos que corresponden a principios del siglo XVI, podría resolver el problema del registro material en cuanto al tema de la aculturación indígena. Sin embargo, es una realidad el hecho de que "Las técnicas de vidriado y el empleo del torno en la Nueva España parten de mediados del siglo XVI, según se infieren de las fuentes históricas" (López Cervantes, 1979:54).

Por esto, puedo afirmar que, muy probablemente, esa vitrificación cerámica sea un indicador del proceso de aculturación. Por otra parte, es necesario aceptar que no se cuenta, en estos momentos, 


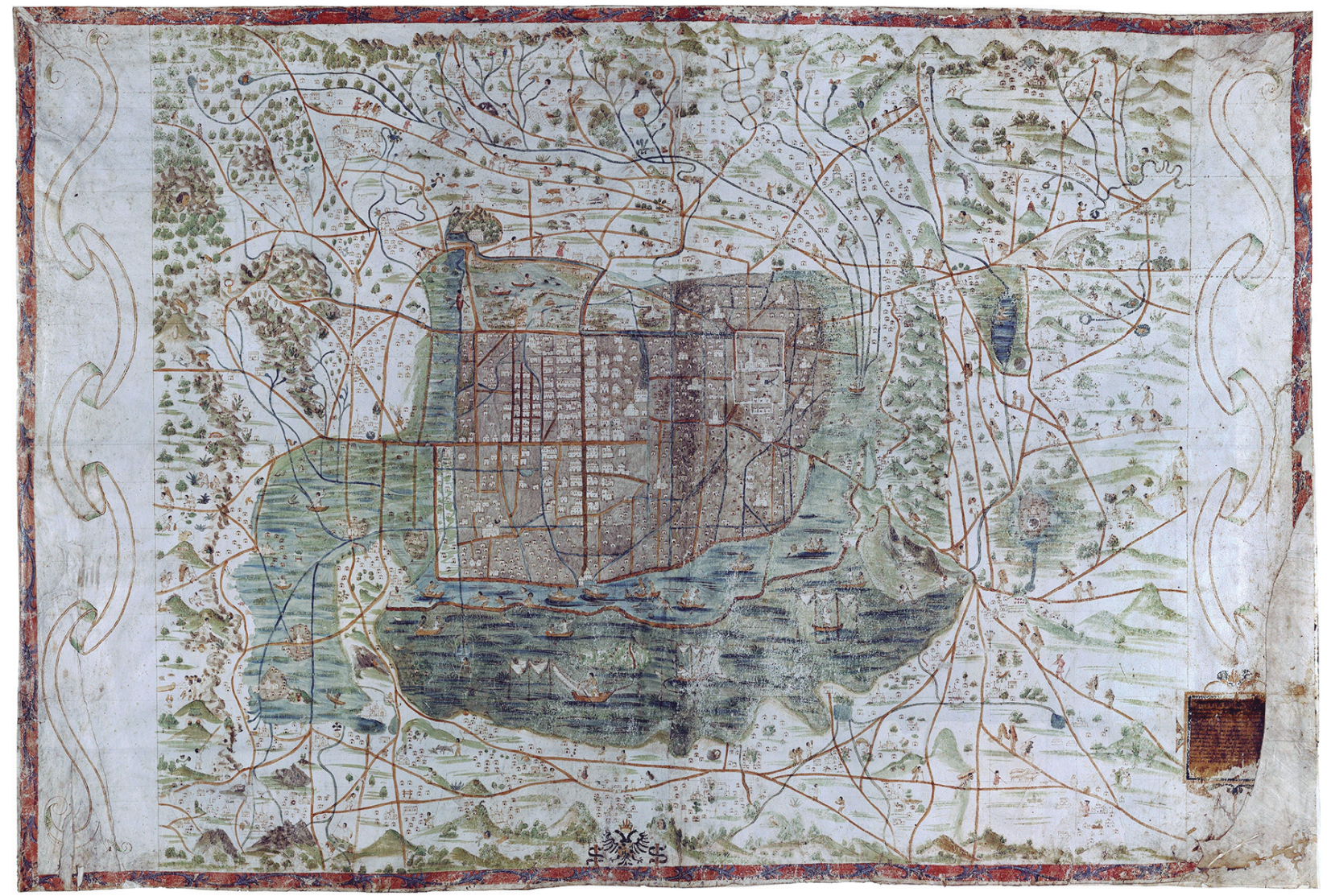

Figura 2. Mapa de Upsala de 1550 (Toussaint, 1940: 137).

con evidencia cerámica que afirme la llegada de dicha técnica a partir de mediados del siglo XVI, por lo que queda fuera del marco temporal de esta investigación.

Por otro lado, sí podemos afirmar que la influencia islámica en materia cerámica en la Nueva España fue muy importante como dice López Cervantes:

"Algunas formas de cerámica árabe, tan especializadas como el albarelo o vaso de farmacia, continuaron elaborándose sin variación en las locerías novohispanas, e incluso dicha forma irá perdurando hasta nuestros días. De esta manera surge la posibilidad de que otras formas pudieran ser una continuación de algunas piezas del mundo árabe del siglo XI, por ejemplo, el caldero de un asa" (López Cervantes, 1979:53).

Ciertamente, la cerámica islámica continuó siendo fabricada y utilizada en la Nueva España. Sin embargo, López Cervantes afirma: "No sabemos con seguridad si en Nueva España llegó a desarrollarse la técnica del reflejo metálico o dorado, acaso debido a la ausencia de colonos o artesanos procedentes de Granada, Paterna o Manises" (López Cervantes, 1979:53).
Esto no significa que no exista la posibilidad de encontrarnos con que sí se fabricó cerámica de procedencia islámica en la Nueva España pero, como mencioné hace unas líneas, hasta este momento contamos con muy poca información sobre la cerámica paleohispánica que es cerámica de los primeros tiempos de contacto cultural en México como para arrojar conclusiones sobre este tema.

En este sentido, también los estudios urbanos han aportado una nueva dimensión al estudio de los procesos de aculturación ya que, al igual que la cultura material, la ciudad tiende a ser construida como una amalgama de ciudades antes vistas por sus constructores y, en muchas ocasiones, las ciudades anteriores sobre las que se asienta la nueva ciudad son reutilizadas por motivos prácticos.

Es decir, la ciudad es un complejo de formas y espacios que retoman estilos antes vistos y vividos y que son combinados con los estilos culturales de la ciudad precedente en el caso de ciudades que se construyen en el mismo sitio que ciudades de culturas anteriores.

En el caso de la primera ciudad de México, su 
urbanismo parece ser del todo defensivo y, por esto mismo, ser un urbanismo práctico que intenta poner a resguardo a los nuevos habitantes de la ciudad, pero enfocado, especialmente, a resguardar el poder recién conseguido por Hernán Cortés. Esta ciudad de México retoma ciertos elementos tenochcas como son las calzadas de la ciudad, las cuales la dotan de una orientación específica relacionada con la fundación de MéxicoTenochtitlan y la localización del Templo Mayor. Es importante mencionar que dicha orientación continúa siendo la principal del centro de la Ciudad de México en el siglo XXI.

Al continuar con el recuento de influencias urbanas que caracterizan a la primera ciudad de México es inevitable denotar que la continuación con el modelo prehispánico es, solamente, una fracción de la influencia cultural que provocó su morfología y los elementos con los que contó. Sin duda alguna, la cultura castellana medieval junto con los elementos que la conformaron fue un foco de influencia cultural que hoy en día es innegable y que abre la investigación del urbanismo de la primera ciudad de México. Esto nos habla de los conquistadores castellanos que llegaron a esas tierras y que entraron en contacto directo con la cultura mexica para, así, comenzar un proceso de aculturación que desembocó en la cultura que, tiempo después, será conocida como cultura Novohispana.

Es por esto último que el periodo Paleohispánico, ha sido muy poco estudiado pero que, también, ha despertado gran curiosidad en los últimos años ya que es un espacio donde los actores fundamentales fueron, por un lado, la población mexica con sus particulares estructuras sociales, económicas, políticas y culturales y, por el otro, los conquistadores castellanos que, como hemos visto a lo largo del artículo, aportaban parte de las estructuras aprendidas también. Sin duda alguna, el personaje que parece ser fundamental en estas interacciones es Hernán Cortés. Esto no necesariamente por la profundidad de sus estructuras culturales sino, muy probablemente, porque es el personaje de la conquista de México más estudiado y, también, el mejor conocido del periodo Paleohispánico en general.

Hernán Cortés podría o no haber tenido estudios en Salamanca (Martínez, 1992: 18). Más allá de ello fue un hombre que a lo largo de la guerra de conquista de México demostró grandes conocimientos militares que después aplicó en la construcción de la ciudad de México como una ciudad defensiva carente de murallas (Tirado, 2017) y, en cuanto a su manera de concebir la conquista que él realizó, era un hombre de mentalidad medieval que trataba de replicar las estructuras que a él le parecían lógicas, mientras el Emperador, Carlos V, tenía un mentalidad muy diferente cuyo objetivo era eliminar los señoríos en la medida de los posible para poder controlar los nuevos territorios ultramarinos desde la Península Ibérica. En concreto, las pugnas entre Hernán Cortés y el Emperador no son más que el conflicto entre dos mentalidades; por un lado, la mentalidad medieval y por el otro la moderna.

Por lo tanto, los procesos culturales son complejos y requieren un trabajo de deconstrucción de las diversas influencias que los integran. Es decir, el contacto entre la cultura castellana y la mexica significa por lo menos el contacto del producto cultural que surgió de la interacción entre las culturas que aportaron rasgos conformadores de la cultura castellana. Por otro lado, sucederá este mismo proceso para la conformación de la cultura mexica y la de los demás pueblos que, poco a poco, entraron en contacto con la de conquista aportada por los castellanos. Es de esa forma cómo podemos acercarnos al estudio de los procesos culturales y, dentro de ellos, al proceso de aculturación que conformará los rasgos que veremos a lo largo del llamado periodo Colonial.

Falta mucho que explorar y desarrollar, ya que tanto la arqueología como el urbanismo son una senda que, sin duda, hay que seguir recorriendo, pero no se debe considerar que estas disciplinas sean las únicas capaces de aportar nuevos datos e interpretaciones que arrojen luz al problema del periodo paleohispánico. Por el contrario, los estudios deben ser multidisciplinares, interdisciplinares y transdisciplinares para lograr una mayor comprensión de este periodo el cual, como mencioné en la introducción de este artículo, se caracteriza por ser coyuntural y representa el final de las estructuras políticas, económicas, sociales y, como consecuencia, culturales de la Edad Media pero, a la vez, se encuentra dentro de una fase en que las ideas renacentistas estaban en boga en algunos ámbitos y latitudes europeas y, en general, dentro del fenómeno histórico que llamamos Edad Moderna con unas estructuras completamente diferentes a las medievales.

En conclusión, el periodo Paleohispánico supone el estudio de uno de los capítulos más interesantes de la historia de México y de España, el momento del contacto cultural y el instante en que 
el último pensamiento medieval creó estructuras y estableció contactos con civilizaciones con las que nunca había interactuado en los territorios americanos. Es un espacio temporal único en el que dichas estructuras fueron creadas de forma práctica por los mismos conquistadores y los frailes y no por las autoridades reales o las eclesiásticas.

Es así como el periodo paleohispánico está marcado directamente por el contacto cultural que resulta innegable y, por lo tanto, por el proceso de aculturación. Además, está enclavado dentro de la amalgama conocida como periodo Colonial Mexicano el cual abarca trecientos años y esto ha dificultado enormemente su estudio.

En lo que se refiere a la teoría de la aculturación considero que ésta sigue siendo vigente, aunque debe ser tomada como buena solamente para periodos de contacto como el Paleohispánico porque, en cuestión de unas pocas décadas, tras la "cristalización cultural", los procesos de aculturación toman nuevas sendas que no están compendiadas dentro de dicha teoría.

En cuanto a lo que supone el estudio cerámico, resulta un elemento indispensable para el estudio de los procesos de aculturación de principios del siglo XVI. Sin embargo, no tenemos suficientes elementos para hacer distinciones claras a nivel estratigráfico que nos hablen de periodos de contacto. Esto está directamente relacionado con la falta de sistematización en la excavación arqueológica y la falta de estudio del material cerámico Paleohispánico.

Por otro lado, el urbanismo ha surgido como un campo de estudio complementario que nos ayuda a comprender estos procesos culturales con sus características y sus cronologías. Los estudios urbanísticos como metodología para los estudios del pasado aún se encuentran en estado de desarrollo pero las primeras aproximaciones (Tirado, 2013 y 2017) han demostrado arrojar una serie de datos que resultan de mucho interés tanto para el conocimiento de las ciudades en si como para denotar el pensamiento de las personas que crearon y planearon dichas ciudades, el ambiente en el que se desenvolvían cuando construyeron o modificaron la urbe, sus influencias culturales e, incluso, las relaciones de poder que los afectaron en ese momento y que quedaron plasmados en el urbanismo de la ciudad.

\section{Bibliografía}

Barrera, J. A. (1999) "El rescate arqueológico en la Catedral y el sagrario Metropolitanos de la Ciudad de México". En E. Matos Moctezuma (ed.): Excavaciones en la catedraly sagrario metropolitanos (PAU), INAH, 21 -50.

Duverger, C. (2005) Cortés la biografia más reveladora. Santillana, Ciudad de México, México.

Fábregas, A. (2012) "De La Teoría de la Aculturación a la Teoría de la Interculturalidad, Educación y Asimilación: El Caso Mexicano" Intercultural Communication Studies 21 (1): 1-8.

Foster, G. (1962) Cultura y conquista: la herencia española de América. Universidad Veracruzana.

Gibson, G. (1967) Los aztecas bajo el dominio español, 15191810. Ed. Siglo XXI, México.

Gosden, C. (2004): Arqueología y colonialismo. El contacto cultural desde 5000 a.C. hasta el presente. Bellaterra arqueología. Barcelona.

López Cervantes, G. (1976) Cerámica colonial en la ciudad de México, Colección Científica, 38, INAH, México.

Matos, E. (1975) Muerte al filo de obsidiana. Editorial Melo S.A. México.

Martínez, J. L. (1992) Hernán Cortés: versión abreviada. FCE. México D.F.

Mier y Terán, L. (2005) Primera traza de la ciudad de México 1524-1536, FCE. México D.F.

Reyes, A. (2008) Nueva España, FCE, México.

Steward, J. (1943) "Acculturation Studies in Latin America: Some Needs and Problems", American Anthropologist, 45, 198 - 204, https://doi.org/ 10.1525/aa.1943.45.2.02a00040.

Tirado, R. O. (2013) Análisis urbanístico de Batalyazes. Trabajo de fin de Máster. Universidad Autónoma de Madrid.

Tirado, R. O. (2017) El urbanismo islámico de la Península Ibéricay la ciudad de México: análisis comparativo. Tesis doctoral. Universidad Autónoma de Madrid. Tesis leída el 20 de septiembre de 2017.

Toussaint, M. (1940) Planos de la ciudad de México. UNAM-Instituto de Investigaciones Estéticas. México. 
